\title{
Assessing the benefit of snow data assimilation for runoff modeling in Alpine catchments
}

\author{
Nena Griessinger ${ }^{1,2}$, Jan Seibert ${ }^{2}$, Jan Magnusson ${ }^{3}$, and Tobias Jonas ${ }^{1}$ \\ ${ }^{1}$ WSL Institute for Snow and Avalanche Research SLF, Davos, Switzerland \\ ${ }^{2}$ Department of Geography, University of Zurich, Zurich, Switzerland \\ ${ }^{3}$ Norwegian Water Resources and Energy Directorate (NVE), Oslo, Norway \\ Correspondence to: Nena Griessinger (nena.griessinger@slf.ch)
}

Received: 22 January 2016 - Published in Hydrol. Earth Syst. Sci. Discuss.: 25 February 2016

Revised: 15 August 201 - Accepted: 2 September 2016 - Published: 22 September 2016

\begin{abstract}
In Alpine catchments, snowmelt is often a major contribution to runoff. Therefore, modeling snow processes is important when concerned with flood or drought forecasting, reservoir operation and inland waterway management. In this study, we address the question of how sensitive hydrological models are to the representation of snow cover dynamics and whether the performance of a hydrological model can be enhanced by integrating data from a dedicated external snow monitoring system. As a framework for our tests we have used the hydrological model HBV (Hydrologiska Byråns Vattenbalansavdelning) in the version HBV-light, which has been applied in many hydrological studies and is also in use for operational purposes. While HBV originally follows a temperature-index approach with time-invariant calibrated degree-day factors to represent snowmelt, in this study the HBV model was modified to use snowmelt time series from an external and spatially distributed snow model as model input. The external snow model integrates three-dimensional sequential assimilation of snow monitoring data with a snowmelt model, which is also based on the temperature-index approach but uses a time-variant degree-day factor. The following three variations of this external snow model were applied: (a) the full model with assimilation of observational snow data from a dense monitoring network, (b) the same snow model but with data assimilation switched off and (c) a downgraded version of the same snow model representing snowmelt with a timeinvariant degree-day factor. Model runs were conducted for 20 catchments at different elevations within Switzerland for 15 years. Our results show that at low and mid-elevations the performance of the runoff simulations did not vary consid-
\end{abstract}

erably with the snow model version chosen. At higher elevations, however, best performance in terms of simulated runoff was obtained when using the snowmelt time series from the snow model, which utilized data assimilation. This was especially true for snow-rich years. These findings suggest that with increasing elevation and the correspondingly increased contribution of snowmelt to runoff, the accurate estimation of snow water equivalent (SWE) and snowmelt rates has gained importance.

\section{Introduction}

Snowmelt provides a dominant contribution to runoff and groundwater storages in mountainous regions. In such areas, modeling snow processes is crucial for resource management as well as for flood and drought forecasting. Snow accumulates and acts as a temporary storage of water that is released as soon as snowmelt occurs. Since erroneous simulations of snow accumulation can bias the amount and timing of simulated snowmelt, accurately modeling both processes is important for runoff predictions. Problems for modelers may occur not only due to the great heterogeneity and variability of these processes, but also due to the limited availability of necessary observational data (Adam et al., 2009; Viviroli and Weingartner, 2004; Viviroli et al., 2011), including erroneous precipitation input data at higher altitudes (Wiesinger, 1993). Additionally, computational resources often constrain operational applications as timely model outputs are required. To cope with these challenges, many hydrological models make use of the temperature-index (TI) melt method instead of 
the energy-balance approach, which has higher input data requirements and is also computationally more demanding (Vehviläinen, 1992; Kumar et al., 2013). TI models can result in sufficient model performance if evaluated at a daily resolution and at the catchment scale (Lang and Braun, 1990; Hock, 2003), provided they use a reasonable parameterization (such as degree-day factor (DDF) and threshold temperature). The basic concept of TI models is to use air temperature as a proxy for the three energy sources that contribute to snowmelt: incoming longwave radiation, absorbed global radiation and sensible heat flux (Ohmura, 2001). The methods differ in their number of parameters, such as threshold values, to parameterize snowfall and melt, ranging from implementations using 2-5, as in the HBV (Hydrologiska Byråns Vattenbalansavdelning) model (Bergström, 1976), to 11 (Irannezhad et al., 2015) parameters. Inappropriate calibration of parameters will fail to accurately describe accumulation and melt rates and lead to a biased duration of the snow season and incorrect melt-out dates (Seibert, 2003). Identifying catchment characteristics that impact hydrological responses (i.e., geology, soil types or land use types) is also critical (Fontaine et al., 2002). Snow models of high complexity have been developed for a great variety of applications and their development is still ongoing. For avalanche research or snow studies on a small scale, simulating detailed processes within the snowpack is of great interest and importance. Otherwise, for operational purposes, which require short computation time and therefore cannot represent snowpack processes in great detail, different approaches are used to simulate snow accumulation and melt. Recently, various methods to assimilate observational snow data for snow cover models have been developed. At the point scale, model improvements due to assimilation of snow water equivalent data from observations were already shown (Magnusson et al., 2014). At the catchment scale and for operational purposes, several studies evaluated the effect of additional information from snow observations with different approaches. Franz et al. (2014) evaluated data assimilation based on a small number of ground-based observation sites within a hindcasting framework. In contrast to predictions of runoff under low-flow conditions, the overall skill of the forecasts could not be significantly improved. Jörg-Hess et al. (2015) improved snow water and runoff volume predictions by replacing simulated snow water equivalent at model initialization with data from measurements. Integrating snow data sets within the calibration procedures is an additional method to improve hydrological models as shown by Finger et al. (2015). A multiple objective calibration based on daily runoff data and snow depth data converted to spatially snow cover data, as introduced by Parajka et al. (2007), could improve snow cover simulations, but not runoff simulations compared to a single objective calibration based on daily runoff data only. Andreadis and Lettenmaier (2006) showed that the assimilation of remotely sensed snow cover area data did not significantly improve the model performance during accumulation, whereas for the snowmelt season small improvements were found. The authors concluded that assimilating snow water equivalent data from observations might be a more successful approach. Therefore, as the main objective of this study, we evaluated the sensitivity of a conceptual runoff model (conceptual in terms of the linear reservoir concept) to the external input of snowmelt data from three different snow models of different complexities. Particularly, we examined the benefit of snow water equivalent data assimilation for hydrological applications in mountainous regions.

\section{Data}

To cover a wide range of elevations and different climatic regions, for this study we chose 20 catchments spread over Switzerland. All of them were at most minimally affected by human activities, such as water regulation or abstraction. A further crucial selection criterion was the availability of the required data. Since, especially at high elevations, the runoff regime of many catchments in Switzerland is affected by man-made installations, the number of possible catchments was highly limited. Catchments analyzed in this study varied in size from 17 to $473 \mathrm{~km}^{2}$ and the mean elevations of these catchments ranged between 560 and $2656 \mathrm{~m}$ a.s.l. (Table 1 and Fig. 1). We grouped the catchments for our analysis based on their mean elevation into three elevation classes: below $1000 \mathrm{~m}$ a.s.l., 1000 to $2000 \mathrm{~m}$ a.s.l. and above $2000 \mathrm{~m}$ a.s.l. Runoff data measured at the catchment outlets of these 20 catchments was provided and checked for plausibility by FOEN (Federal Office of the Environment). According to the temporal resolution of the model output, we aggregated the hourly runoff records into daily sums. For the data assimilation for the full snow model used in this study we considered daily snow depth measurements from both manual and automatic monitoring stations (see red stars in Fig. 1 for locations). All 320 stations used were part of either the MeteoSwiss (Federal Office of Meteorology and Climatology) or the SLF (WSL Institute for Snow and Avalanche Research) snow station networks in Switzerland, covering elevations between 210 and $2950 \mathrm{~m}$ a.s.l. and located on open, flat terrain. Out of approximately 600 available stations, only 320 were used after a careful selection process to avoid sites that were influenced by wind or frequent sensor failures, or known to systematically deviate from representative measurements. Daily data from the morning measurements between 1 September 1998 and 31 August 2013 were carefully checked for missing values or erroneous readings and corrected where necessary. These values were replaced using a stochastic gap filling model that accounts for data from the same station before and after the gap, as well as for data from neighboring stations at similar elevations. Temperature data were obtained from 220 stations and interpolated using an inverse distance weighting approach as described in Magnusson et al. (2014), which considers both horizontal and 
Table 1. Characteristics of 20 Swiss catchments in this study.

\begin{tabular}{|c|c|c|c|c|c|c|c|c|}
\hline Number & Station name & $\begin{array}{l}\text { Area } \\
{\left[\mathrm{km}^{2}\right]}\end{array}$ & $\begin{array}{l}\text { Min } \\
\text { elevation } \\
\text { [m a.s.l.] }\end{array}$ & $\begin{array}{l}\text { Max } \\
\text { elevation } \\
\text { [ma.s.1.] }\end{array}$ & $\begin{array}{l}\text { Mean } \\
\text { elevation } \\
\text { [ma.s.1.] }\end{array}$ & $\begin{array}{l}\text { Elevation } \\
\text { class }\end{array}$ & $\begin{array}{l}\text { Begin } \\
\text { snowmelt } \\
\text { [month-day] }\end{array}$ & $\begin{array}{l}\text { End } \\
\text { snowmelt } \\
\text { [month-day] }\end{array}$ \\
\hline 2202 & Ergolz - Liestal & 276 & 305 & 1087 & 577 & 1 & $01-01$ & 03-01 \\
\hline 2126 & Murg - Wängi & 77 & 501 & 911 & 640 & 1 & $01-14$ & 03-14 \\
\hline 2034 & Broye - Payerne, Caserne d'aviation & 416 & 450 & 1402 & 721 & 1 & $01-14$ & $03-14$ \\
\hline 2343 & Langeten - Huttwil, Häberenbad & 61 & 592 & 1032 & 757 & 1 & $01-14$ & $03-14$ \\
\hline 2374 & Necker - Mogelsberg, Aachsäge & 89 & 649 & 1359 & 948 & 1 & $02-14$ & $04-14$ \\
\hline 2321 & Cassarate - Pregassona & 74 & 286 & 1809 & 954 & 1 & $02-14$ & $04-14$ \\
\hline 2603 & Ilfis - Langnau & 188 & 699 & 1695 & 1040 & 2 & $02-21$ & $04-21$ \\
\hline 2634 & Kleine Emme - Emmen & 473 & 440 & 2261 & 1044 & 2 & $02-21$ & $04-21$ \\
\hline 2179 & Sense - Thörishaus, Sensematt & 355 & 609 & 2028 & 1072 & 2 & 03-01 & $05-01$ \\
\hline 2609 & Alp - Einsiedeln & 82 & 845 & 1577 & 1096 & 2 & $02-21$ & $04-21$ \\
\hline 2409 & Emme - Eggiwil, Heidbüel & 127 & 770 & 2007 & 1296 & 2 & $02-21$ & $04-21$ \\
\hline 2300 & Minster - Euthal, Rüti & 59 & 918 & 1994 & 1345 & 2 & 03-07 & $05-07$ \\
\hline 2203 & Grande Eau - Aigle & 130 & 579 & 2830 & 1546 & 2 & $03-14$ & $05-14$ \\
\hline 2605 & Verzasca - Lavertezzo, Campioi & 188 & 546 & 2590 & 1656 & 2 & $03-14$ & $05-14$ \\
\hline 2276 & Grosstalbach - Isenthal & 43 & 931 & 2682 & 1794 & 2 & 03-14 & $05-14$ \\
\hline 2232 & Allenbach - Adelboden & 31 & 1360 & 2587 & 1907 & 2 & $03-14$ & $05-14$ \\
\hline 2366 & Poschiavino - La Rösa & 17 & 1920 & 3005 & 2316 & 3 & $04-14$ & $06-14$ \\
\hline 2304 & Ova dal Fuorn - Zernez, Punt la Drossa & 56 & 1797 & 2903 & 2337 & 3 & $04-14$ & $06-14$ \\
\hline 2327 & Dischmabach - Davos, Kriegsmatte & 42 & 1772 & 2869 & 2349 & 3 & $04-14$ & $06-14$ \\
\hline 2256 & Rosegbach - Pontresina & 67 & 1833 & 3721 & 2686 & 3 & $05-01$ & $07-01$ \\
\hline
\end{tabular}

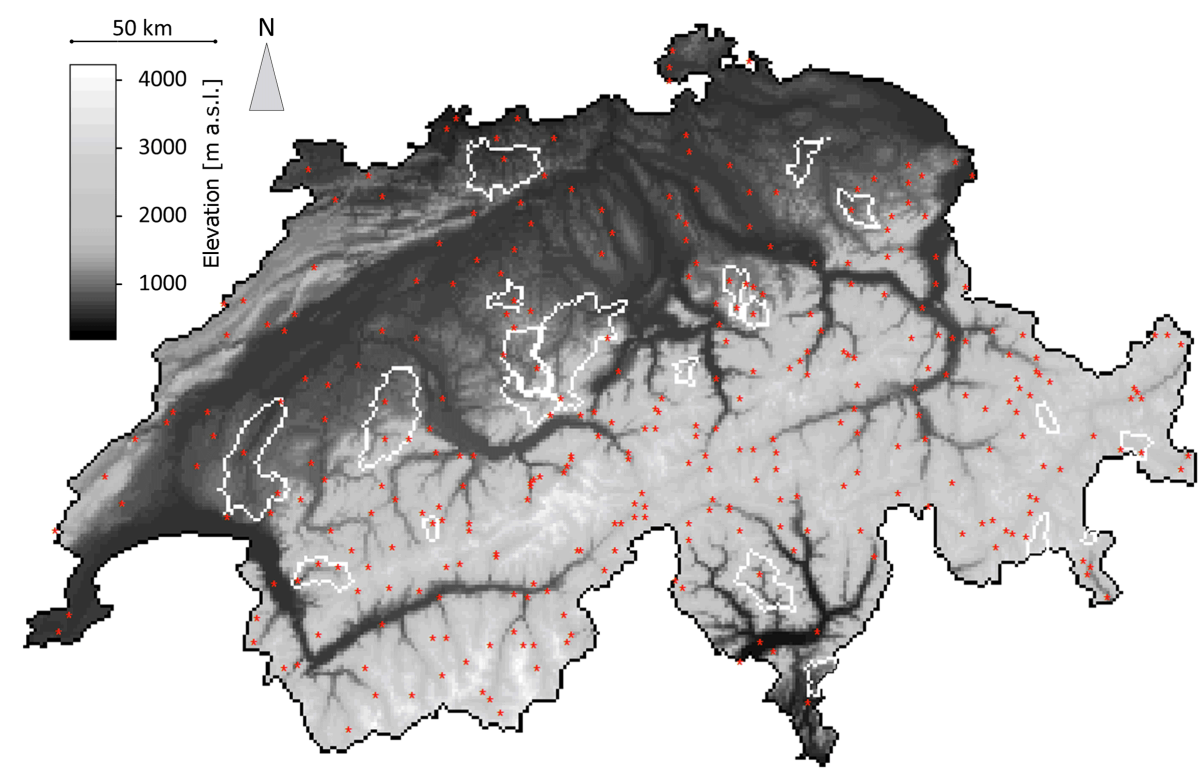

Figure 1. Locations of snow observation stations (red stars) and 20 studied catchments (white border lines) in Switzerland.

vertical distances between measurement stations and interpolated grid cells. A variable weighting factor was used to determine the influence of horizontally near but vertically distant stations. The resolution of the resulting temperature grid data set was $1 \mathrm{~km} \times 1 \mathrm{~km}$. Precipitation data were also required as a gridded input data set. We used a daily product (RhiresD) with a spatial resolution of $2 \mathrm{~km} \times 2 \mathrm{~km}$ available from MeteoSwiss. The product is based on a dense precipitation gauge network with approximately 500 stations within
Switzerland. Methodological details are described in Frei and Schär (1998), Frei et al. (2006) and Isotta et al. (2014). 


\section{Methods}

\subsection{Hydrological model}

The hydrological model HBV (Bergström, 1976, 1992, 1995; Lindström et al., 1997) in the version HBV-light (Seibert and Vis, 2012) was used to simulate runoff at the 20 selected catchments. HBV requires a time series of precipitation, air temperature and potential evaporation to simulate runoff for a specific catchment. Potential evaporation was calculated following the methods of Priestley and Taylor (1972). In the HBV snow routine, precipitation is expected to be solid below a certain temperature threshold and multiplied by a correction factor to account for possible undercatch and to compensate for the missing snow interception. Snowmelt is usually calculated using the same threshold temperature and a DDF. Up to a certain fraction, liquid water can be stored in the snowpack and refreezes if temperatures are below the threshold temperature. In our study, however, we disabled this snow routine of the HBV model and replaced snowmelt as well as rain input with data coming both from the external snow model. Groundwater recharge and actual evaporation were simulated in a soil routine depending on the actual water storage. A response routine consisting of three linear reservoirs and a routing routine using a triangular weighting function follow. Runoff data observed at the outlet of all catchments considered in this study were used for calibration and validation of the model. More details are available in Seibert and Vis (2012). To evaluate the performance of the hydrological model in response to the input from different variants of the external snowmelt model, we focused our analysis on the main melt period, denoted below as snowmelt season. Although the onset and duration of the snowmelt season vary from year to year, we have determined a fixed snowmelt season for each individual catchment (Table 1), based on the average timing of the first snowmelt runoff in spring and the average duration until $75 \%$ of the snow has melted. Two approaches were chosen to split the available runoff data into separate data sets for calibration and validation. The first approach was to use all years for calibration except one, which was used for validation. This so-called leave-one-out procedure was repeated so that each year was used for validation once. The second approach was differential split sampling (Klemeš, 1986), where the snow-poor and normal years were used for calibration and the snow-rich years were used for validation. This separation into different snow year groups was done individually for each catchment. To optimize the parameter set of the hydrological model for each catchment and each of the input data sets within the calibration period, we ran a genetic calibration algorithm as described in Seibert (2000) with 5000 model runs and 1000 runs for local optimization. This was done individually for each of the above model configurations, as well as for the benchmark model. As the objective function, we used the
Nash-Sutcliffe model efficiency (Nash and Sutcliffe, 1970) computed for the catchment-specific snowmelt season.

\subsection{Snow model}

The external snow model framework, which we used in this study instead of the snow routine built in the HBV model, also simulates snowmelt by a TI approach but in addition allows for integration of observational snow data using a data assimilation scheme. While some details on the external snow model framework are given below, a full description of model and data assimilation methods is available in Magnusson et al. (2014). We applied three versions of this model, denoted M1 to M3. Version M1 includes the full model and data assimilation scheme (an approach unavailable in the internal snow routine of HBV), whereas M2 an M3 are downgraded versions of M1 as described below. Several characteristics are common to all model versions described below. First, a threshold temperature differentiates whether precipitation falls as snowfall or rain. However, the models allow for mixed precipitation in a range close to the threshold temperature (see Eq. (10) and the corresponding description in Magnusson et al., 2014). Second, fractional snow-covered area (SCF) is parameterized using modeled snow depth and terrain parameters that were derived from a $25 \mathrm{~m}$ digital elevation model according to Helbig et al. (2015). Third, all three model versions allow for the snow cover to hold a fraction of liquid water. Fourth, all model versions consider the influence of topography on snow distribution and redistribution in mountainous terrain. Slope- and aspect-dependent correction functions were trained using a set of high-resolution snow depth maps from airborne lidar acquisitions in the European Alps as presented in Grünewald and Lehning (2015), and applied at a subgrid $25 \mathrm{~m}$ spatial resolution. This procedure ensured accurate inference of areal mean snow depths from snow and precipitation measurements on flat field sites. In the following section, we describe the three versions of the snow model used in this study:

- TI snowmelt model with data assimilation and timevarying DDF (M1): this model is the same as that described in detail in Magnusson et al. (2014). Using an elaborated TI approach, daily snowmelt at each grid cell was calculated if a certain threshold temperature is exceeded. The DDF defines the possible melt rate per day and per degree temperature above the threshold. For M1, the DDF varied as a function of season between a minimal $\left[1.0 \mathrm{~mm}^{\circ} \mathrm{C}^{-1} \mathrm{day}^{-1}\right]$ and maximal $\left[4.5 \mathrm{~mm}^{\circ} \mathrm{C}^{-1} \mathrm{day}^{-1}\right]$ value using a sinusoidal function (see Eq. (12) in Magnusson et al., 2014). The DDF is independent of elevation. For the data assimilation, the daily measured snow depth data at all stations were first converted to snow water equivalents (SWE) using a snow density model, which is based on the methods of Jonas et al. (2009) and Martinec and Rango (1991). Second, by applying an optimal interpolation 


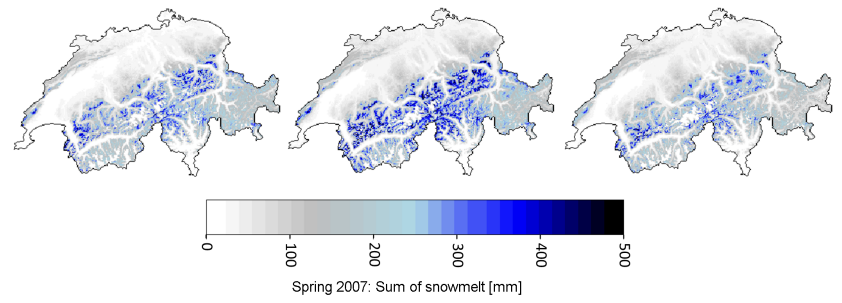

Figure 2. Cumulative snowmelt during the snowmelt season 2007 as calculated by the snow model method M1 (full model with data assimilation, left), M2 (full model without data assimilation, middle) and M3 (simplified model, right). The sums between the three model methods differ depending on the use of observational snow data assimilation and the use of different DDFs.

approach, the SWE data were used to correct the computed snowfall amounts. Finally, the simulated melt rates and model state variables (SWE and liquid water content) were updated using the ensemble Kalman filter with the same SWE data. Both the optimal interpolation scheme and the ensemble Kalman filter were set up using spatially correlated error statistics. With such an approach, often called three-dimensional data assimilation, the point snow observations influence the gridded simulation results even at locations lacking observations. For more details about the model, and the data assimilation method in particular, see Magnusson et al. (2014).

- TI snowmelt model with time-varying DDF without data assimilation (M2): in this version, the same elaborated TI approach as in M1 was applied to simulate snow accumulation and melt at each grid cell based on the same input data grids as in M1. The DDF seasonal variations are equal to those in M1. The only difference concerns the data assimilation procedures, which were switched off in M2, such that observed SWE data were not used to update the initial estimates on snow accumulation and melt rates.

- TI snowmelt model using a constant DDF without data assimilation (M3): this version differs from M2 with respect to the DDF. Here the DDF does not show seasonal variations but is assumed to be constant over the season. The average DDF of $2.5 \mathrm{~mm}^{\circ} \mathrm{C}^{-1}$ day $^{-1}$ was chosen, which is a good compromise if used for the full winter season. For comparison only, complementary analyses were performed with the constant DDF of $4.0 \mathrm{~mm}^{\circ} \mathrm{C}^{-1} \mathrm{day}^{-1}$, which is more appropriate if used for a late snowmelt season only. Note that M3 represents the type of snow routine used in HBV except for that DDF is a model parameter determined by calibration in $\mathrm{HBV}$, whereas it is a pre-defined value in $\mathrm{M} 3$.

Replacing a TI model with another TI model, and not with an energy-balance or snowpack-physics model, may appear

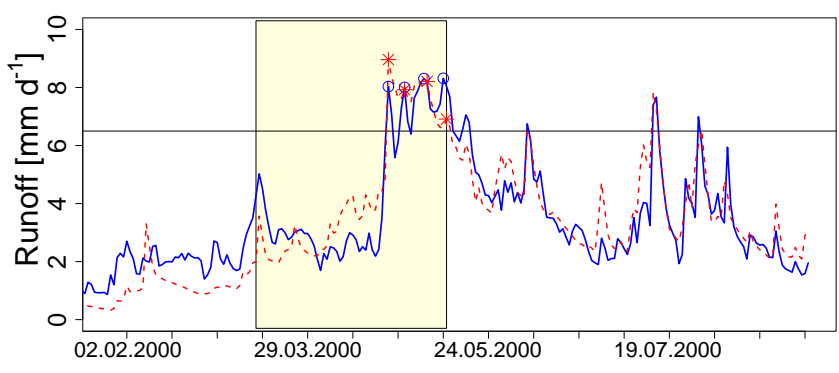

Figure 3. Graphical explanation of how to calculate $E_{\mathrm{PF}}$. The yellow background shows a catchment-specific snowmelt season window within which the efficiency criteria were computed. The horizontal line indicates the threshold of 1.5 times the mean observed runoff (blue line) above which measured peak flow events (blue circles) are detected. Red stars present corresponding events of the simulated runoff (dashed red line). See Sect. 3.3 for details.

unusual at first glance. However, if concerned with conceptual hydrological modeling at a daily timescale, the TI model framework used here constituted an ideal testing environment. To provide daily snowmelt rates, the dynamic data assimilation framework within M1 represents current state-ofthe art methodology in operational snow hydrological monitoring. Since it accounts for measured snow depletion rates at hundreds of monitoring sites, it provides the best possible input to the hydrological model. Even with data assimilation switched off (M2), if validated against snow lysimeter data at daily time steps, the performance is almost on par with the output of top-notch energy-balance models (Magnusson et al., 2015). Only the concept of using a constant DDF (M3) could result in a severely downgraded performance, as already seen by Lang and Braun (1990). Hence, the triplet, M1, M2, M3, provides a ranked set of input options, which allows for an evaluation of the sensitivity of conceptual hydrological modeling on the input from different types of snow models. This ultimately was the purpose of the study, rather than testing the performance of a specific runoff model (i.e., HBV). As mentioned above, HBV originally uses a TI snowmelt routine, which is similar to our external model version M3. However, as part of $\mathrm{HBV}$, the constant DDF is a free parameter to be optimized during calibration of the snowmelt season. Hence, to provide a benchmark for our performance tests, we also ran the HBV model with the original snow routine switched on. We used these runs as an upper benchmark, since the HBV snow routine was tuned by calibration to allow for the maximum possible performance of the runoff model for each individual catchment. In contrast, we created a lower benchmark by assuming all precipitation to be rain, i.e., a no-snow-model scenario. These two benchmarks allowed for scaling of the performances, which were achieved when using M1 to M3 to provide input to HBV. All model variants were run for the whole study period on a daily time step at $1 \mathrm{~km}$ spatial resolution. During the snowmelt season, the three snow model methods created individual spatial 
pattern of simulated snowmelt. As an illustrative example, the cumulative sums of snowmelt between 1 February 2007 and 30 April 2007 are shown in Fig. 2. As expected for the snowmelt season, M2 yielded higher amounts of snowmelt compared to M3 due to differences in the DDF. In this particular year, the observations used for the assimilation did not support the high melt rates as predicted by M2, resulting in M1 to calculate lesser amounts of snowmelt.

\subsection{Validation methods}

Timing of snowmelt onset and of runoff events due to snowmelt affects the availability of water resources and influences flooding and droughts (Semmens and Ramage, 2013). Therefore, it is crucial to simulate and to evaluate the timing of streamflow accurately when comparing snowmelt models. Several efficiency criteria are used in the literature for evaluating hydrological models and should be selected carefully depending on the aim of the validation (Krause et al., 2005). To assess the performance of the hydrological model in combination with the input options from our set of snow models, we chose the following two criteria. First, since we were interested in how precise single peak flow events due to snowmelt could be simulated when integrating data from the different snow model approaches, we used the "peak flow efficiency for snowmelt season" $E_{\mathrm{PF}}$. Figure 3 illustrates the procedure to calculate this measure. Observed peak flow events during the snowmelt season (yellow period in Fig. 3) that exceed a certain threshold (defined as 1.5 times of the mean runoff during snowmelt season; horizontal line in Fig. 3) were picked and denoted as $Q_{\text {peak obs } i}$ (blue circles in Fig. 3). The maximum simulated runoff in a time window of 1 day before and after each of the $n$ observed peak flow events was taken as simulated reference value $Q_{\text {peak sim } i}$ (red stars in Fig. 3). The reference values did not necessarily have to be local peaks or greater than a certain threshold (Eq. (1); Seibert, 2003).

$E_{\mathrm{PF}}=1-\frac{\sum_{i=1}^{n}\left|Q_{\text {peak obs } i}-Q_{\text {peak sim } i}\right|}{\sum_{i=1}^{n} Q_{\text {peak obs } i}}$

Additionally, the frequently used Nash-Sutcliffe efficiency of runoff $E_{Q}$ (Eq. 2) according to Nash and Sutcliffe (1970), which is also supposed to be sensitive to peak flow events (Krause et al., 2005), was chosen and applied to the defined snowmelt season.

$E_{Q}=1-\frac{\sum_{i=1}^{m}\left(Q_{\mathrm{obs} i}-Q_{\mathrm{sim} i}\right)^{2}}{\sum_{i=1}^{m}\left(Q_{\mathrm{obs} i}-\operatorname{mean}\left(Q_{\mathrm{obs}}\right)\right)^{2}}$,

where $i$ represents all (1 to $m$ ) days within the snowmelt season, and $Q_{\mathrm{obs} i}$ and $Q_{\mathrm{sim} i}$ are observed and simulated runoff at day $i$, respectively. This was also used as the objective function for the genetic calibration algorithm (GAPoptimization) within the hydrological model framework.

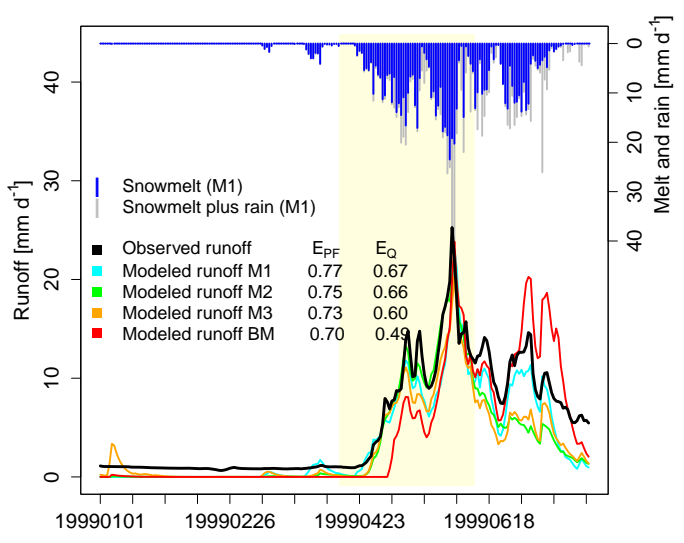

Figure 4. Observed and modeled runoff for the Dischma catchment for 1999, as well as water input from snowmelt and rain modeled with method M1. The upper benchmark model BM in red.

\section{Results and discussion}

Both efficiency metrics were calculated for (a) each catchment and (b) each of the two calibration experiments. The performance statistics are discussed separately for each of the three groups of catchments depending on mean elevation.

\subsection{Example of runoff simulation for a representative catchment}

To look for differences between the three snow model methods, individual catchments and years were selected. Representing a catchment at high elevations, results for the Dischma catchment (EZG 2327, gauge Davos Kriegsmatte) with a mean elevation of $2349 \mathrm{~m}$ a.s.l. are shown in Fig. 4. The yellow background displays the catchment-specific snowmelt season during which the bulk of the snowmelt typically occurs. The blue and gray lines at top of the graph indicate the snowmelt input to the hydrological model from M1 excluding and including rain, respectively, in this example for the record-high snow year 1999. The observed runoff is shown by the black curve, while the different colored curves indicate the simulations with M1, M2 and M3. The curves as well as the performance metrics achieved by the differential splitsample experiment demonstrate that for this catchment, the M1 model as input to the hydrological framework provided the best runoff simulations, even though the differences are small. Note however, that in this example M1 particularly outperforms the other models in the month of July, which is outside the standard evaluation period.

\subsection{Model performance across elevation classes: leave-one-out sample}

First, we used the leave-one-out approach to calibrate the hydrological model. The leave-one-out approach represents a typical scenario in operational conceptual runoff modeling, 

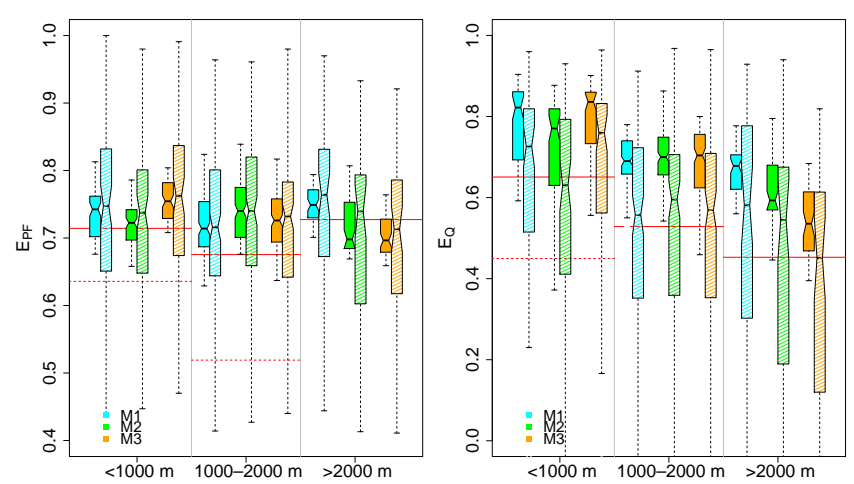

Figure 5. Results of the leave-one-out approach. $E_{\mathrm{PF}}$ (left panel) and $E_{Q}$ (right panel) for each elevation class and snowmelt model. For the individual elevation classes and melt models, the left box plots (darker colors) show the results for the calibration period, and the right box plots (lighter colors) show the results for the validation period. The whisker boxes represent the median (center line), the interquartile range (25th-75th percentile; box outline) and highest/lowest performance within the interquartile range ( \pm 1.5 times of the interquartile range; whiskers). The benchmark performance is denoted by a solid red line (upper benchmark) and a dashed red line (lower benchmark), and the latter only displayed if within the range of the axis limits.

i.e., to use as much data as possible for calibration and to apply the resulting parameter values to the current season. Results grouped according to mean catchment height are presented below (Fig. 5). Using this calibration procedure for catchments with mean elevation below $1000 \mathrm{~m}$ a.s.l., the hydrological model showed good results independent of which snow model was used as input to the hydrological model framework. Even without using a snow model at all (i.e., the lower benchmark), the runoff model resulted in lower but still positive performance values, indicating that the choice of snow model within a conceptual runoff modeling framework is of less importance when dealing with catchments at lower elevations. Similarly for catchments with mean elevation between 1000 and $2000 \mathrm{~m}$ a.s.l. the differences between the three model runs were small. While $E_{\mathrm{PF}}$ levels were maintained relative to our assessment for catchments below $1000 \mathrm{~m}$ a.s.l., they were separated more clearly from the benchmark model runs, which dropped in performance. $E_{Q}$ values, on the other hand, decreased for all the M1, M2, M3 and the benchmark model runs. Only for the highest elevation class did the results based on M1 significantly outperform the other model runs, and even reached better $E_{\mathrm{PF}}$ values than most simulations at lower elevation classes. Even the model runs based on M2 performed better than those based on M3. This shows that the benefit of better snowmelt input data for conceptual runoff modeling only seems to pay off if considering catchments above a certain elevation. At lower elevation, differences between the model input options could be mitigated by way of the calibration procedure. Fur- ther, while results based on M1 showed a relatively constant performance across all elevation classes in both $E_{\mathrm{PF}}$ and $E_{Q}$, this was not the case for results based on M2 and M3, which deteriorated with increasing elevation. Looking at all elevation classes, the median performance of the M1 runs was always higher than the upper benchmark. This was also mostly the case for M2 and M3. This result shows that all versions of the external snow model performed unexpectedly well in combination with the hydrological framework even though they were not included in the calibration procedure. Finding instances where even M3 (which uses a prescribed DDF) outperforms the upper benchmark model (which relies on a calibrated DDF) may appear counter-intuitive. However, note that M1, M2, M3 have been particularly trained for an optimal performance in the Swiss Alps, e.g., regarding the representation of processes like liquid water content, refreezing, cold content dynamics, the partitioning of rain and snow, and redistribution of snow in steep terrain. Further, calibrating HBV for the melt season only could result in a DDF that is too high during the snow accumulation period, which would inhibit an accurate timing of the meltwater release (c.f. Fig. 4). On the contrary, M3 features a more moderate DDF of $2.5 \mathrm{~mm}^{\circ} \mathrm{C}^{-1} \mathrm{day}^{-1}$, allowing for a more balanced performance over the entire snow season. The above results demonstrate a benefit of using an advanced snowmelt modeling system in the context of conceptual hydrological modeling, even if the benefit seems comparably small and restricted to catchments above a certain elevation. Other studies that evaluated the influence of integrating snow water equivalent data into hydrological models showed similar results (Finger et al., 2015; Jörg-Hess et al., 2015). Only a few studies have used direct assimilation of ground-based snow data. Due to limited availability of ground observations, assimilating remotely sensed snow data is a more common practice but requires further inversion methods, which is quite challenging to implement and induces additional uncertainties (Andreadis and Lettenmaier, 2006). Several studies used satellite observations of snow cover extent in different assimilation schemes to update snow models. Clark et al. (2006) as well as Thirel et al. (2013) could slightly improve runoff predictions by assimilation of snow-covered area using the ensemble Kalman filter and the particle assimilation filter, respectively. As in the above studies, we focused on a catchment-specific snowmelt season and used two performance measures that evaluated the ability of the models to capture peak flow events, among other characteristics of the hydrograph. Simulating such events is of great importance, especially for operational flood forecasting purposes. While the performance of well-calibrated models may be adequate independent of model complexity (Hock, 2003; Magnusson et al., 2015), we are particularly interested in the model performance in extreme years, when the snowmelt contribution greatly increases flood risks. This is why in the second set of modeling experiments we singled out snow-rich years as a validation data set to generate both a more challenging and 

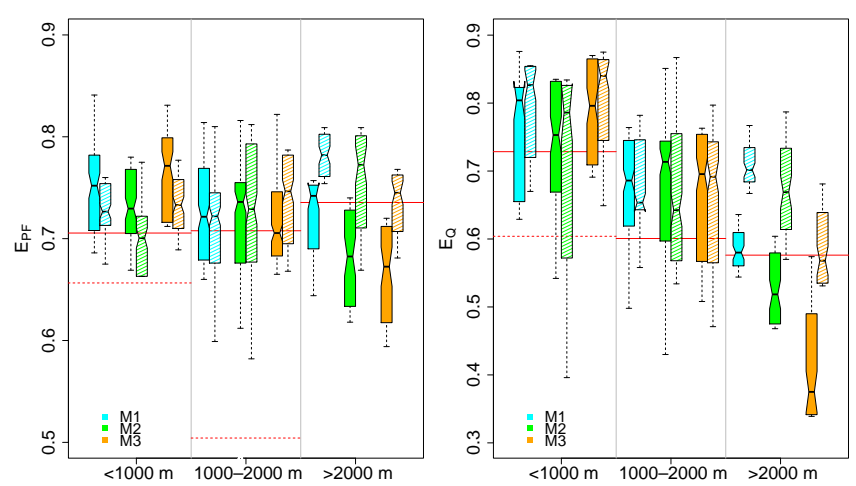

Figure 6. Results of the differential split-sample approach. $E_{\mathrm{PF}}$ (left panel) and $E_{Q}$ (right panel) for each elevation class and snowmelt model. For the individual elevation classes and melt models, the left box plots (darker colors) show the results for the calibration period, and the right box plots (lighter colors) show the results for the validation period. The whisker boxes represent the median (center line), the interquartile range (25th-75th percentile; box outline) and highest/lowest performance within the interquartile range ( \pm 1.5 times of the interquartile range; whiskers). The benchmark performance is denoted by a solid red line (upper benchmark) and a dashed red line (lower benchmark), and the latter only displayed if within the range of the axis limits.

more relevant test scenario. For the snow-rich years, we selected the 6 years with the highest cumulative snowmelt individually for each catchment.

\subsection{Model performance across elevation classes: differential split sample}

For the differential split-sample approach, snow-rich years were used to validate the runoff models. As expected, the analysis using the differential split-sample approach revealed similar performance patterns compared to the leave-one-out approach, but with increased differences between model runs (Fig. 6). As seen before, at low and mid-elevation classes the differences between the three model versions as well as between calibration and validation were comparably small. The median values of efficiencies for each model version ranged between 0.7 and $0.8\left(E_{\mathrm{PF}}\right)$ respectively 0.75 and $0.85\left(E_{Q}\right)$. As seen before, at high elevations, model results based on M1 were superior (significantly for $E_{Q}$ ) to those based on $\mathrm{M} 2$, which in turn outperformed the model runs based on M3. However, the differences between the three runs were considerably larger than those seen with the leave-one-out approach. Another notable difference between both calibration methods was that the differential split-sample approach led to significantly higher $E_{Q}$ for validation years compared to calibration years, while the opposite was the case when using the leave-one-out approach. Both findings strongly suggest that the benefit of advanced snowmelt input data for conceptual runoff modeling is particularly valuable in situations that feature a strong snowmelt component (high el- evation, snow-rich years). Both $E_{\mathrm{PF}}$ and $E_{Q}$ for M1-based model runs show an exceptional performance at high elevation for validation years, which highlights the value of snow data assimilation when concerned with forecasting snowmelt related floods. An additional analysis was performed with M3 using a DDF of $4.0 \mathrm{~mm}^{\circ} \mathrm{C}^{-1}$ day $^{-1}$ (results not included in figures). This is a typical value found in the literature for high elevations with melting conditions later in the season (Martinec et al., 1983). As expected, compared to the standard DDF of $2.5 \mathrm{~mm}^{\circ} \mathrm{C}^{-1}$ day $^{-1}$ in M3, the additional model runs resulted in slightly better performance metrics at high elevations with a later onset of snowmelt (catchments above $2000 \mathrm{~m}$ a.s.1.), but considerably worse performance in all other model runs.

\subsection{Model performance for high elevation catchments: leave-one-out sample}

The validation of the differential split-sample experiment showed that the three external snow models provided the best runoff simulations for snow-rich years, specifically for catchments with a mean elevation of above $2000 \mathrm{~m}$ a.s.l. In a further analysis, we ordered the single validation years individually by catchment for the leave-one-out approach from snow poor to snow rich based on peak SWE. This procedure allowed testing of whether there was a trend in the runoff performance metrics associated with the snow amount of single years. Such a trend was indeed evident, as seen in Fig. 7. Independent of the snow model used, the best results were achieved when validating the model performance during snow-rich years regarding both $E_{\mathrm{PF}}$ and $E_{Q}$. The performance measures discussed above were computed for a catchment-specific pre-defined fixed snowmelt season, which was based on the typical timing of observed snowmelt runoff. Extending the snowmelt season to 120 days gave similar results (data not shown) with the same relative differences between M1, M2, M3, but with a lower overall performance due to the decreasing relevance of snowmelt as the snow-covered area declines. While our approach allowed us to focus on the sensitivity of runoff modeling to different approaches for estimating snowmelt, it has four main implications to the interpretation of the results. First, $E_{Q}$ values tend to be lower if calculated over a short period, and values may not be comparable to $E_{Q}$ data from assessment of multiyear or multi-season data sets, in particular if analyzing daily runoff data that do not encompass diurnal variations. Second, within a pre-defined season, the variation of a time-varying DDF as used in M2 is small. Especially at low elevations and early in the year, the DDF of M2 and M3 do not differ much and therefore produces similar runoff simulations with comparable performance. According to Lang and Braun (1990) and Magnusson et al. (2015), a clearer benefit of using a flexible instead of a fixed DDF would have been expected if used within a longer time window. Third, at low elevations snowmelt may occur sporadically and not necessarily 

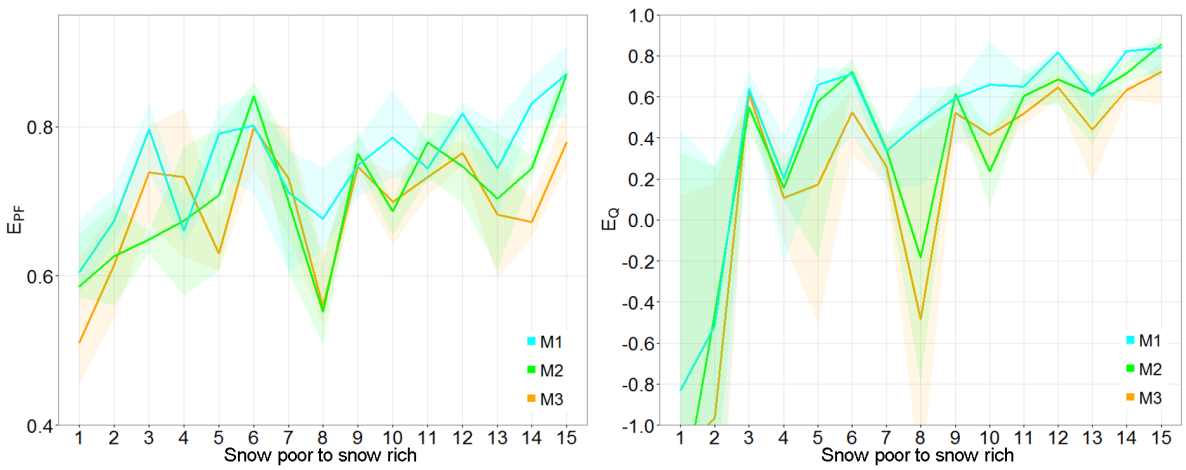

Figure 7. Results of the leave-one-out approach for catchments with mean elevation above $2000 \mathrm{~m}$ a.s.1. Median (solid lines) and interquartile (25th-75th percentile; shading) range of $E_{\mathrm{PF}}$ (left panel) and $E_{Q}$ (right panel) for validation years ordered from snow-poor (index $=1$ ) to snow-rich (index $=15$ ) years.

within a pre-defined season. At high elevations, it is also possible that the main melt does not occur within the catchmentspecific snowmelt season due to longer melt-out duration of extremely snow-rich years. Consequently, if snowmelt occurred outside of the validation period, it would not affect the performance statistics. This may have partly suppressed differences between the three different snow models. Finally, note that seasonal $E_{\mathrm{PF}}$ and $E_{Q}$ statistics are two metrics out of several possible evaluation criteria. While we also tested other metrics, these were not further integrated to the discussion, given that the results were similar compared to the performance data presented above.

\section{Conclusions}

Based on daily runoff data measured over a period of 15 years at 20 catchments in Switzerland, we evaluated the sensitivity of a conceptual hydrological modeling framework to snowmelt input from snow models of different complexity. The most complex snow model integrated threedimensional sequential assimilation of snow monitoring data with a snowmelt model based on the temperature-index approach. In contrast, the simplest snow model represented snowmelt with a constant degree-day factor, and did not include any data assimilation. The snow models were combined with the HBV model in the version HBV-light (Seibert and Vis, 2012) to produce a runoff record. The performance of the HBV runs based on snowmelt data from the snow models was assessed by way of performance metrics evaluated during the snowmelt season only. Our results showed that advanced methods to calculate snowmelt as input to conceptual runoff models only improved model performance if considering snow-dominated catchments. At low elevations, differences between the model input options were found to be minor. For higher elevation catchments, however, snowmelt input from the data assimilation framework consistently provided the best results. Further analysis demonstrated con- siderably higher performance metrics for snow-rich years as compared to years with little snow. In contrast to earlier studies, which have shown that assimilation of snow-covered area only has limited impact on runoff simulations, our results indicate that the assimilation of snow water equivalent data can have a larger benefit for accurate streamflow predictions. This finding highlights the value of choosing the appropriate snow data assimilation methods, and perhaps even more important, selecting the correct variable for assimilation when concerned with operational forecasting of snowmelt related floods.

Acknowledgements. This study was partly funded by the Federal Office of the Environment (FOEN). We thank MeteoSwiss for access to the meteorological data and FOEN for providing riverrunoff observations used in this study. Thanks to Manfred Stähli and Massimiliano Zappa for helpful discussions and to Nathalie Chardon for reviewing the English of this article.

Edited by: R. Woods

Reviewed by: J. Parajka, O. Rössler, and one anonymous referee

\section{References}

Adam, J. C., Hamlet, A. F., and Lettenmaier, D. P.: Implications of global climate change for snowmelt hydrology in the twenty-first century, Hydrol. Process., 23, 962-972, 2009.

Andreadis, K. M. and Lettenmaier, D. P.: Assimilating remotely sensed snow observations into a macroscale hydrology model, Adv. Water Resour., 29, 872-886, 2006.

Bergström, S.: Development and application of a conceptual runoff model for Scandinavian catchments, Lund Institute of Technology, University of Lund, Sweden, Bulletin Series A, 52, 134 pp., 1976.

Bergström, S.: The HBV model: Its structure and applications, Swedish Meteorological and Hydrological Institute, 35 pp., 1992. 
Bergström, S.: The HBV model, edited by: Singh, V., Computer Models of Watershed Hydrology, Water Resources Publications, Highlands Ranch, Colorado, USA, 443-476, 1995.

Clark, M. P., Slater, A. G., Barrett, A. P., Hay, L. E., McCabe, G. J., Rajagopalan, B., and Leavesley, G. H.: Assimilation of snow covered area information into hydrologic and land-surface models, Adv. Water Resour., 29, 1209-1221, 2006.

Finger, D., Vis, M., Huss, M., and Seibert, J.: The value of multiple data set calibration versus model complexity for improving the performance of hydrological models in mountain catchments, Water Resour. Res., 51, 1939-1958, 2015.

Fontaine, T., Cruickshank, T., Arnold, J., and Hotchkiss, R.: Development of a snowfall-snowmelt routine for mountainous terrain for the soil water assessment tool (SWAT), J. Hydrol., 262, 209223, 2002.

Franz, K. J., Hogue, T. S., Barik, M., and He, M.: Assessment of SWE data assimilation for ensemble streamflow predictions, J. Hydrol., 519, 2737-2746, 2014.

Frei, C. and Schär, C.: A precipitation climatology of the Alps from high-resolution rain-gauge observations, Int. J. Climatol., 18, 873-900, 1998.

Frei, C., Schöll, R., Fukutome, S., Schmidli, J., and Vidale, P. L.: Future change of precipitation extremes in Europe: Intercomparison of scenarios from regional climate models, J. Geophys. Res.Atmos., 111, D06105, doi:10.1029/2005JD005965, 2006.

Grünewald, T. and Lehning, M.: Are flat-field snow depth measurements representative? A comparison of selected index sites with areal snow depth measurements at the small catchment scale, Hydrol. Process., 29, 1717-1728, 2015.

Helbig, N., van Herwijnen, A., Magnusson, J., and Jonas, T.: Fractional snow-covered area parameterization over complex topography, Hydrol. Earth Syst. Sci., 19, 1339-1351, doi:10.5194/hess-19-1339-2015, 2015.

Hock, R.: Temperature index melt modelling in mountain areas, J. Hydrol., 282, 104-115, 2003.

Irannezhad, M., Ronkanen, A.-K., and Kløve, B.: Effects of climate variability and change on snowpack hydrological processes in Finland, Cold Reg. Sci. Technol., 118, 14-29, 2015.

Isotta, F. A., Frei, C., Weilguni, V., Perčec Tadić, M., Lassègues, P., Rudolf, B., Pavan, V., Cacciamani, C., Antolini, G., Ratto, S. M., et al.: The climate of daily precipitation in the Alps: development and analysis of a high-resolution grid dataset from pan-Alpine rain-gauge data, Int. J. Climatol., 34, 1657-1675, 2014.

Jonas, T., Marty, C., and Magnusson, J.: Estimating the snow water equivalent from snow depth measurements in the Swiss Alps, J. Hydrol., 378, 161-167, 2009.

Jörg-Hess, S., Griessinger, N., and Zappa, M.: Probabilistic Forecasts of Snow Water Equivalent and Runoff in Mountainous Areas*, J. Hydrometeorol., 16, 2169-2186, 2015.

Klemeš, V.: Operational testing of hydrological simulation models, Hydrol. Sci. J., 31, 13-24, 1986.

Krause, P., Boyle, D., and Bäse, F.: Comparison of different efficiency criteria for hydrological model assessment, Adv. Geosci., 5, 89-97, 2005.

Kumar, M., Marks, D., Dozier, J., Reba, M., and Winstral, A.: Evaluation of distributed hydrologic impacts of temperature-index and energy-based snow models, Adv. Water Resour., 56, 77-89, 2013.
Lang, H. and Braun, L.: On the information content of air temperature in the context of snow melt estimation, IAHS Publ, 190, 347-354, 1990.

Lindström, G., Johansson, B., Persson, M., Gardelin, M., and Bergström, S.: Development and test of the distributed HBV-96 hydrological model, J. Hydrol., 201, 272-288, 1997.

Magnusson, J., Gustafsson, D., Hüsler, F., and Jonas, T.: Assimilation of point SWE data into a distributed snow cover model comparing two contrasting methods, Water Resour. Res., 50, 78167835, 2014.

Magnusson, J., Wever, N., Essery, R., Helbig, N., Winstral, A., and Jonas, T.: Evaluating snow models with varying process representations for hydrological applications, Water Resour. Res., 51, 2707-2723, 2015.

Martinec, J. and Rango, A.: Indirect evaluation of snow reserves in mountain basins, International Association of Hydrological Sciences. IAHS/AISH Publ., 602, 111-119, 1991.

Martinec, J., Rango, A., and Major, E.: The snowmelt-runoff model (SRM) user's manual, NASA Ref. Publ. 1100, 1983.

Nash, J. E. and Sutcliffe, J. V.: River flow forecasting through conceptual models part I - A discussion of principles, J. Hydrol., 10, 282-290, 1970.

Ohmura, A.: Physical basis for the temperature-based melt-index method, J. Appl. Meteorol., 40, 753-761, 2001.

Parajka, J., Merz, R., and Blöschl, G.: Uncertainty and multiple objective calibration in regional water balance modelling: case study in 320 Austrian catchments, Hydrol. Process., 21, 435446, 2007.

Priestley, C. and Taylor, R.: On the assessment of surface heat flux and evaporation using large-scale parameters, Mon. Weather Rev., 100, 81-92, 1972.

Seibert, J.: Multi-criteria calibration of a conceptual runoff model using a genetic algorithm, Hydrol. Earth Syst. Sci., 4, 215-224, doi:10.5194/hess-4-215-2000, 2000.

Seibert, J.: Reliability of model predictions outside calibration conditions, Hydrol. Res., 34, 477-492, 2003.

Seibert, J. and Vis, M. J. P.: Teaching hydrological modeling with a user-friendly catchment-runoff-model software package, Hydrol. Earth Syst. Sci., 16, 3315-3325, doi:10.5194/hess-16-33152012, 2012.

Semmens, K. A. and Ramage, J. M.: Recent changes in spring snowmelt timing in the Yukon River basin detected by passive microwave satellite data, The Cryosphere, 7, 905-916, doi:10.5194/tc-7-905-2013, 2013.

Thirel, G., Salamon, P., Burek, P., and Kalas, M.: Assimilation of MODIS snow cover area data in a distributed hydrological model using the particle filter, Remote Sens., 5, 5825-5850, 2013.

Vehviläinen, B.: Snow cover models in operational watershed forecasting, National Board of Waters and the Environment Helsinki, Finland, 112 pp., 1992.

Viviroli, D. and Weingartner, R.: The hydrological significance of mountains: from regional to global scale, Hydrol. Earth Syst. Sci., 8, 1017-1030, doi:10.5194/hess-8-1017-2004, 2004.

Viviroli, D., Archer, D. R., Buytaert, W., Fowler, H. J., Greenwood, G. B., Hamlet, A. F., Huang, Y., Koboltschnig, G., Litaor, M. I., López-Moreno, J. I., Lorentz, S., Schädler, B., Schreier, H., Schwaiger, K., Vuille, M., and Woods, R.: Climate change and mountain water resources: overview and recommendations for 
research, management and policy, Hydrol. Earth Syst. Sci., 15, 471-504, doi:10.5194/hess-15-471-2011, 2011.

Wiesinger, T.: Accurate measurement of snowfall: development of two innovative precipitation gages based on the analysis of existing errors, Universität Wien, Inst. f. Meteorologie und Geophysik, 1993. 